\title{
Experimental Investigation and Multiobjective Optimization of Turning Duplex Stainless Steels
}

\author{
Rastee D. Koyee, ${ }^{1}$ Uwe Heisel, ${ }^{1}$ Siegfried Schmauder, ${ }^{2}$ and Rocco Eisseler ${ }^{1}$ \\ ${ }^{1}$ Institute for Machine Tools, University of Stuttgart, Holzgartenstraße 17, 70174 Stuttgart, Germany \\ ${ }^{2}$ IMWF, University of Stuttgart, Pfaffenwaldring 32, 70569 Stuttgart, Germany \\ Correspondence should be addressed to Rastee D. Koyee; rastee.ali@ifw.uni-stuttgart.de
}

Received 6 September 2014; Accepted 10 November 2014; Published 3 December 2014

Academic Editor: Godfrey C. Onwubolu

Copyright (c) 2014 Rastee D. Koyee et al. This is an open access article distributed under the Creative Commons Attribution License, which permits unrestricted use, distribution, and reproduction in any medium, provided the original work is properly cited.

\begin{abstract}
This paper addresses experimental investigations of turning EN 1.4462 and EN 1.4410 duplex stainless steel grades with multilayer coated carbide inserts. Single-point wet and dry longitudinal turning tests of cylindrical bars are conducted; cutting forces, effective cutting powers, and tool wear are measured. The parametric influences of cutting speed, feed rate, and process conditions on the cutting performances such as resultant cutting force, specific effective cutting power, and flank wear are analyzed and proper conclusions are drawn. Nature-inspired metaheuristic bat algorithm is employed to handle the multiobjective optimization of the conflicting performances. Finally, the optimum cutting condition for each process condition can be selected from calculated Pareto optimal fronts by the user according to the planning requirements.
\end{abstract}

\section{Introduction}

Duplex stainless steels (DSSs) can be defined as a family of stainless steels whose structures are approximately $50 \%$ austenite and $50 \%$ ferrite, and its physical properties are a combination of the ferritic and the austenitic grades. In addition to their relatively low cost, they combine the best attributes of both austenitic and ferritic stainless steels which provide high strength and ductility with good resistance to corrosion (including stress corrosion cracking). Therefore, they are most commonly used when a combination of high mechanical strength and high corrosion resistance is required and are increasingly seen as an attractive alternative to the conventional stainless steels. However, owing to their high tensile and yield strength (roughly twice the yield strength of their counterpart austenitic grades, see Table 1), high work hardening rate, low thermal conductivity, high fracture toughness, strong tendency to form the built-up edge (BUE), and relatively high austenite and nitrogen content, modern duplex stainless steels are regarded as poorly machinable materials [1].

Over the past several years, few researchers have investigated the machining of duplex stainless steels. For instance,
Bordinassi et al. studied the main effects of the turning in the superficial integrity of the duplex stainless steel ASTM A890-Gr6A. Their findings have shown that the smaller feed rate, smaller cutting speed, and the greater cutting depth provided the smaller values for the tensile residual stress, the smaller surface roughness, and the greater microhardness [2]. Królczyk et al. examined the influence of cutting parameters on surface roughness after DSS turning process. Their results have clearly showed that the feed rate was the main influencing factor on the surface roughness [3]. Królczyk et al. determined the coated carbide tool life and drew the tool wear curve when machining DSS. Their results have confirmed no effect of cutting speed and cooling on metallographic structure and designated the optimum cutting speed between 130 and $150 \mathrm{~m} / \mathrm{min}$ and [4]. Nomani et al. have conducted machinability tests on duplex alloys SAF 2205 and SAF 2507, while employing austenite stainless steel $316 \mathrm{~L}$ as a benchmark during drilling. Both duplex alloys displayed poorer machinability responses, with 2507 being worst [5]. Oliveira Jr. et al. have studied the turning operation of SAF 2507 and its influence on the alloy's corrosion resistance in practical applications. Their results have indicated that turning with PVD-coated inserts under high-pressure cooling resulted in 
TABLE 1: Workpiece materials properties.

\begin{tabular}{lcc}
\hline Chemical composition \%weight & EN 1.4462 & EN 1.4410 \\
\hline $\mathrm{C}$ & 0.018 & 0.015 \\
$\mathrm{Cr}$ & 22.42 & 24.92 \\
$\mathrm{Ni}$ & 5.44 & 6.91 \\
$\mathrm{Mo}$ & 3.12 & 4.06 \\
$\mathrm{Mn}$ & 0.84 & 0.75 \\
$\mathrm{Si}$ & 0.37 & 0.25 \\
$\mathrm{~N}$ & 0.18 & 0.3 \\
$\mathrm{P}$ & 0.025 & 0.021 \\
$\mathrm{~S}$ & 0.0033 & 0.0007 \\
\hline & Mechanical properties & \\
Yield strength (MPa) & 514 & 579 \\
Tensile (MPa) & 737 & 826 \\
Hardness (BHN) & 212 & 236 \\
Elongation (\%) & 41 & 40 \\
\hline
\end{tabular}

long tool lives, good workpiece roughness, and high corrosion resistance of the material after machining. The most frequent wear mechanism found during the tests was notch wear, while the main tool wear mechanism was attrition [6]. Philip Selvaraj et al. have optimized dry turning parameters of two different grades of nitrogen alloyed duplex stainless steel by using Taguchi method. Their results revealed that the feed rate is the most significant parameter influencing the surface roughness and cutting force. On the other hand, the cutting speed was identified as the most significant parameter influencing the tool wear [7].

In this paper, multiobjective bat algorithm (MOBA) is applied to optimize the conflicting turning performances such as resultant cutting force, specific effective cutting power, and maximum flank wear. The algorithm suggests sets of optimum solutions for the parameter setting of DSS turning process. The models of conflicting performances were obtained from experimental data. The rest of this paper is organized as follows. The description of MOBA is introduced in Section 2. Discussions of the obtained experimental results are presented in Section 3. Modeling of performance characteristics is described in Section 4. Results of MOBA are shown in Section 5 and some conclusions are given in Section 6.

\section{Multiobjective Bat Algorithm (MOBA)}

Nature-inspired metaheuristic algorithms are based on strategies that try to imitate the behavior observed in species found in nature to update a population of candidates to solve optimization problems. They have contributed significantly to the development of new optimization techniques. These algorithms can be classified as population-based and trajectory-based. BA is a population-based swarm intelligence algorithm which is inspired by the echolocation of microbats. Echolocation is an advanced hearing based navigation system used by bats and some other animals to detect objects in their surroundings by emitting a sound to the environment. In general echolocation calls are characterized by three features, namely, pulse frequency, pulse emission rate, and loudness (intensity). In general the frequency $\varphi$ in a range $\left[\varphi_{\min }, \varphi_{\max }\right]$ corresponds to a range of wavelengths $\left[\Omega_{\min }, \Omega_{\max }\right]$. For example, a frequency range of $[20 \mathrm{kHz}$, $500 \mathrm{kHz}$ ] corresponds to a range of wavelengths from $0.7 \mathrm{~mm}$ to $17 \mathrm{~mm}$ in reality. Obviously, one can choose the ranges freely to suit different applications. In order to develop a standard bat algorithm, the following approximate or idealized rules are applied.

(a) All bats use echolocation to sense distance, and they also "know" the difference between food/prey and background barriers in some magical way.

(b) Bats fly randomly with velocity $v_{i}$ at position $x_{i}$ with a frequency $\varphi_{\min }$, varying wavelength, and loudness $A_{0}$ to search for prey. They can automatically adjust the wavelength (or frequency) of their emitted pulses and adjust the rate of pulse emission $r \in[0,1]$, depending on the proximity of their target.

(c) Although the loudness can vary in many ways, we assume that the loudness varies from a large (positive) $A_{0}$ to a minimum constant value $A_{\text {min }}$.

For the bats in simulations, we have to define the rules how their positions $x_{i}$ and velocities $v_{i}$ in a $d$-dimensional search space are updated. The new solutions $x_{t i}$ and velocities $v_{t i}$ at time step $t$ are given by

$$
\begin{aligned}
f_{i} & =f_{\min }+\left(f_{\max }-f_{\min }\right) \beta, \\
v_{i}^{t+1} & =v_{i}^{t}+\left(x_{i}^{t}-x_{*}\right) f_{i}, \\
x_{i}^{t+1} & =x_{i}^{t}+v_{i}^{t},
\end{aligned}
$$

where $\beta \in[0,1]$ is a random vector drawn from a uniform distribution. Here $x_{*}$ is the current global best location (solution) which is located after comparing all the solutions among all the $n$ bats at each iteration $t$. Based on the above approximations and idealization, the basic steps of the multiobjective bat algorithm (MOBA) can be summarized as the pseudocode shown in Algorithm 1.

2.1. Pareto Optimality. The concept of Pareto optimum was formulated by Vilfredo Pareto in the XIX century and constitutes by itself the origin of research in multiobjective optimization. A solution vector $u=\left(u_{1}, \ldots, u_{n}\right)^{T} \in F$ is said to dominate another vector $v=\left(v_{1}, \ldots, v_{n}\right)^{T}$ if and only if $u_{i} \leq$ $v_{i}$ for all $i \in\{1, \ldots, n\}$ and $\exists i \in\{1, \ldots, n\}: u_{i}<v_{i}$. In other words, no component of $u$ is larger than the corresponding component of $v$, and at least one component is smaller. Similarly, we can define another dominance relationship $\preccurlyeq$ by

$$
u \leq v \Longleftrightarrow u \prec v \vee u=v .
$$

It is worth pointing out that, for maximization problems, the dominance can be defined by replacing $\prec$ with $\succ$. Therefore, a point $x_{*} \in F$ is called a nondominated solution if no solution can be found that dominates it [8]. The Pareto front PF of 
Objective functions $f_{1}(x), \ldots, f_{K}(x), x=\left(x_{1}, \ldots, x_{d}\right)^{T}$

Initialize the bat population $x_{i}(i=1,2, \ldots, n)$ and $v_{i}$

for $j=1$ to $N$ (points on Pareto fronts)

while $(t<$ Max number of iterations)

Generate new solutions and update by (1)

if $\left(\right.$ rand $>r_{i}$ )

Random walk around a selected best solution end if

Generate a new solution by flying randomly

if $\left(\right.$ rand $\left.<\mathbf{A}_{\mathbf{i}} \& \mathbf{f}\left(\mathbf{x}_{\mathbf{i}}\right)<\mathbf{f}\left(\mathbf{x}_{*}\right)\right)$

Accept the new solutions,

and increase $r_{i}$ \& reduce $A_{i}$ end if

Rank the bats and find the current best $x_{*}$ end while

Record $x_{*}$ as a non-dominated solution

end

Postprocess results and visualization

Algorithm 1: Multiobjective bat algorithm (MOBA) [10].

a multiobjective can be defined as the set of nondominated solutions so that

$$
\mathrm{PF}=\left\{s \in S \mid \nexists s^{\prime} \in S: s^{\prime} \prec s\right\}
$$

or in terms of the Pareto optimal set in the search space

$$
\mathrm{PF}^{*}=\left\{x \in F \mid \nexists x^{\prime} \in F: G\left(x^{\prime}\right) \prec G(x)\right\} \text {, }
$$

where $G=\left(G_{1}, \ldots, G_{K}\right)^{T}$. To obtain a good approximation to Pareto front, a diverse range of solutions should be generated using efficient techniques [9].

\section{Materials and Methods}

Full-factorial cutting tests are carried out on a CNC lathe (CTX 420 Linear V5) with maximum drive power $25 \mathrm{~kW}$ and a speed range of 35-7000 rpm. The workpiece materials for turning tests were standard DSS EN 1.4462 and super DSS EN 1.4410. Their chemical compositions and mechanical properties are given in Table 1.

The cutting tools used in the tests were made by Sandvik Coromant AB, Sweden. The solid carbide inserts were of type CNMG 120408-MM 2025. The coating consists of $5.5 \mu \mathrm{m}$ CVD TiCN- $\mathrm{Al}_{2} \mathrm{O}_{3}$-TiN layers on a substrate which features excellent resistance to both mechanical and thermal shock. The triple coating consists of a $2.5 \mu \mathrm{m}$ thick TiCN at the bottom followed by a $2 \mu \mathrm{m}$ multilayer $\mathrm{TiN} / \mathrm{Al}_{2} \mathrm{O}_{3}$ at the middle and finally a thin $(\sim 1 \mu \mathrm{m})$ outer coating of TiN on top. The inserts were mounted on a right hand style PCLNL2525M-12 ISO type tool holder with tool geometry as follows: including angle $=80^{\circ}$, back rake angle $=-6^{\circ}$, clearance angle $=$ $5^{\circ}$, approach angle $=95^{\circ}$, and cutting edge radius $\approx 40 \mu \mathrm{m}$. The cutting and process conditions are given in Table 2. It has been designed to study the effects of the workpiece materials,
TABLE 2: Cutting and process conditions.

\begin{tabular}{lc}
\hline Cutting speed, $\mathrm{m} / \mathrm{min}$ & 100,180 \\
Feed rate, $\mathrm{mm} / \mathrm{rev}$ & $0.15,0.2,0.25,0.3,0.35,0.4$ \\
Cutting depth, $\mathrm{mm}$ & 1 \\
Process condition & Dry, wet \\
\hline
\end{tabular}

process, and cutting conditions on the constants in Kienzle's cutting force model.

The width of maximum flank wear $\left(V B_{\max }\right)$ was periodically measured during progressive tool wear experiments using an optical microscope after every cutting pass of machining operation. The criterion for tool life was $V B_{\max }=$ $0.6 \mathrm{~mm}$ or catastrophic tool failure of the tool edge. During the turning tests, the main cutting force $\left(F_{c}\right)$, axial force $\left(F_{a}\right)$, and radial force $\left(F_{r}\right)$ were measured using a Kistler type 9129A three-component piezoelectric dynamometer, which was connected to a charged Kistler type 5070A amplifier and personal computer through an analog to digital converter card. The resultant cutting force is calculated using

$$
R=\sqrt{F_{c}^{2}+F_{a}^{2}+F_{r}^{2}} .
$$

Thereafter, specific cutting pressures such as main $k_{c}$, feed $k_{f}$, and radial $k_{r}$ are calculated using the following equations:

$$
\begin{aligned}
& k_{c}=\frac{F_{c}}{f a_{p}}, \\
& k_{a}=\frac{F_{a}}{f a_{p}}, \\
& k_{r}=\frac{F_{r}}{f a_{p}},
\end{aligned}
$$

where $f$ is the feed rate and $a_{p}$ is the cutting depth. The effective cutting power $\left(P_{\text {eff. }}\right)$ component of the motor is always proportional to the torque emitted by the motor; therefore it is often used as a signal within the control system for quantifying the motor load. During the course of each cutting test, the electrical current consumed by the machine tool was measured from the external effective-power modules which were installed between the frequency convertor and the motor. In the present study, the range of energy requirements at the drive motor of the machine tool while turning DSS is estimated using the specific effective cutting power which can be calculated using the following formula:

$$
P_{s}=\frac{P_{\text {eff. }}}{v_{c} f a_{p}}=\frac{\sqrt{3} U I \cos \varphi}{v_{c} f a_{p}},
$$

where $U$ is the line voltage in volts, $I$ is the line current in ampere, $\cos \varphi$ is the power factor, and $v_{c}$ is the cutting speed. The experimental setup is shown in Figure 1. In the present research, high-resolution thermographic camera of brand VarioCam head Hires 640 by InfraTec is used to film the chip formation and measure the chip temperature at a resolution of $640 \times 480$ pixels. 


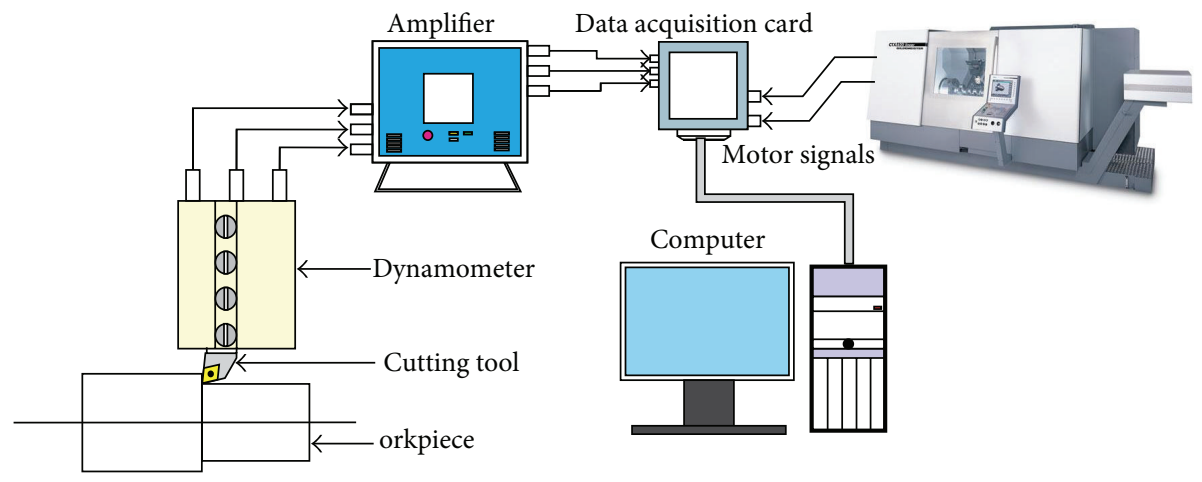

FIGURE 1: Diagram of the experimental setup.

TABLE 3: Summary of the models coefficients.

\begin{tabular}{|c|c|c|c|c|c|c|c|}
\hline \multirow{2}{*}{ Model } & \multirow{2}{*}{ Proc. cond. } & \multicolumn{3}{|c|}{ EN 1.4462} & \multicolumn{3}{|c|}{ EN 1.4410} \\
\hline & & $k_{1.1}$ & $a$ & $b$ & $k_{1.1}$ & $a$ & $b$ \\
\hline \multirow{2}{*}{$F_{c}$} & Dry & 2367 & -0.28 & 0.1 & 2920 & -0.29 & 0.08 \\
\hline & Wet & 2215 & -0.26 & 0.13 & 2471 & -0.26 & 0.19 \\
\hline \multirow{2}{*}{$F_{f}$} & Dry & 852 & -0.48 & 0.47 & 1182 & -0.41 & 0.47 \\
\hline & Wet & 737 & -0.49 & 0.53 & 1126 & -0.64 & 0.5 \\
\hline \multirow{2}{*}{$F_{r}$} & Dry & 741 & -0.27 & 0.23 & 921 & -0.22 & 0.32 \\
\hline & Wet & 899 & -0.46 & 0.18 & 908 & -0.23 & 0.3 \\
\hline \multirow{2}{*}{$R$} & Dry & 2550 & -0.32 & 0.2 & 3145 & -0.31 & 0.21 \\
\hline & Wet & 2431 & -0.32 & 0.22 & 2811 & -0.35 & 0.28 \\
\hline
\end{tabular}

\section{Results and Discussion}

4.1. Specific Cutting Pressure. The specific cutting pressure is often considered as an indication of the machinability of a given work material. The higher the specific cutting pressure is, the lower the machinability of the work material is. The specific cutting pressures for turning EN 1.4462 and EN 1.4410 were calculated from the cutting data employing (6) and the results are shown in Figure 2. Based on a quick review of the results,

(1) no drastic difference between the cutting pressures of dry and wet conditions was observed. However, overall wet machining shows an improvement in the machining performance through lower cutting pressures;

(2) specific cutting pressures when machining EN 1.4462 DSS were seen lower than the specific cutting pressures when machining EN 1.4410. Therefore, it can be predicted that the machinability index EN 1.4410 will be smaller than the machinability index of EN 1.4462;

(3) the cutting pressures generally showed a decreasing trend with increasing cutting speed and feed rate (see Figure 2). As it can be seen in this figure, the maximum cutting pressures occur at low cutting speeds and low feed rates. Thus, in order to achieve low cutting pressures, machining process should be done in high cutting speeds and high feed rates;
(4) modified Kienzle formula can be applied to evaluate the parametric effects of cutting conditions on the cutting forces as follows:

$$
F=k_{1.1}\left(\frac{v_{c}}{100}\right)^{a}(f)^{(1-b)}
$$

where $F$ represents the described cutting and resultant forces, $k_{1.1}$ is the specific cutting pressure for $1 \mathrm{~mm}^{2}$ cross-sectional area of the cut, and $a$ and $b$ are constants. The model fitting has employed the least square method. Summary of models coefficients is listed in Table 3.

To avoid misleading conclusions, the adequacy of the fitted models should be checked. Therefore, analysis of variance (ANOVA) for 95\% a level of confidence was performed in order to estimate the predictive accuracy of the models and to determine the relative significances of the different factors using Matlab. From the ANOVA shown in Table 4, it is apparent that almost all correlation coefficients are near to 1 , showing that significant terms have been included in the model and that the model is capable of predicting the responses, $P$ value estimators are all close to zero (much lower than 0.05 corresponding to the confidence interval) which show the significant effect of factors on the corresponding response, and $F$-values are much larger than 1 , which indicate that factors have a significant effect on the response. Moreover, variations of cutting force, feed force, and radial force towards cutting speed and feed rate are studied in dry and wet machining 

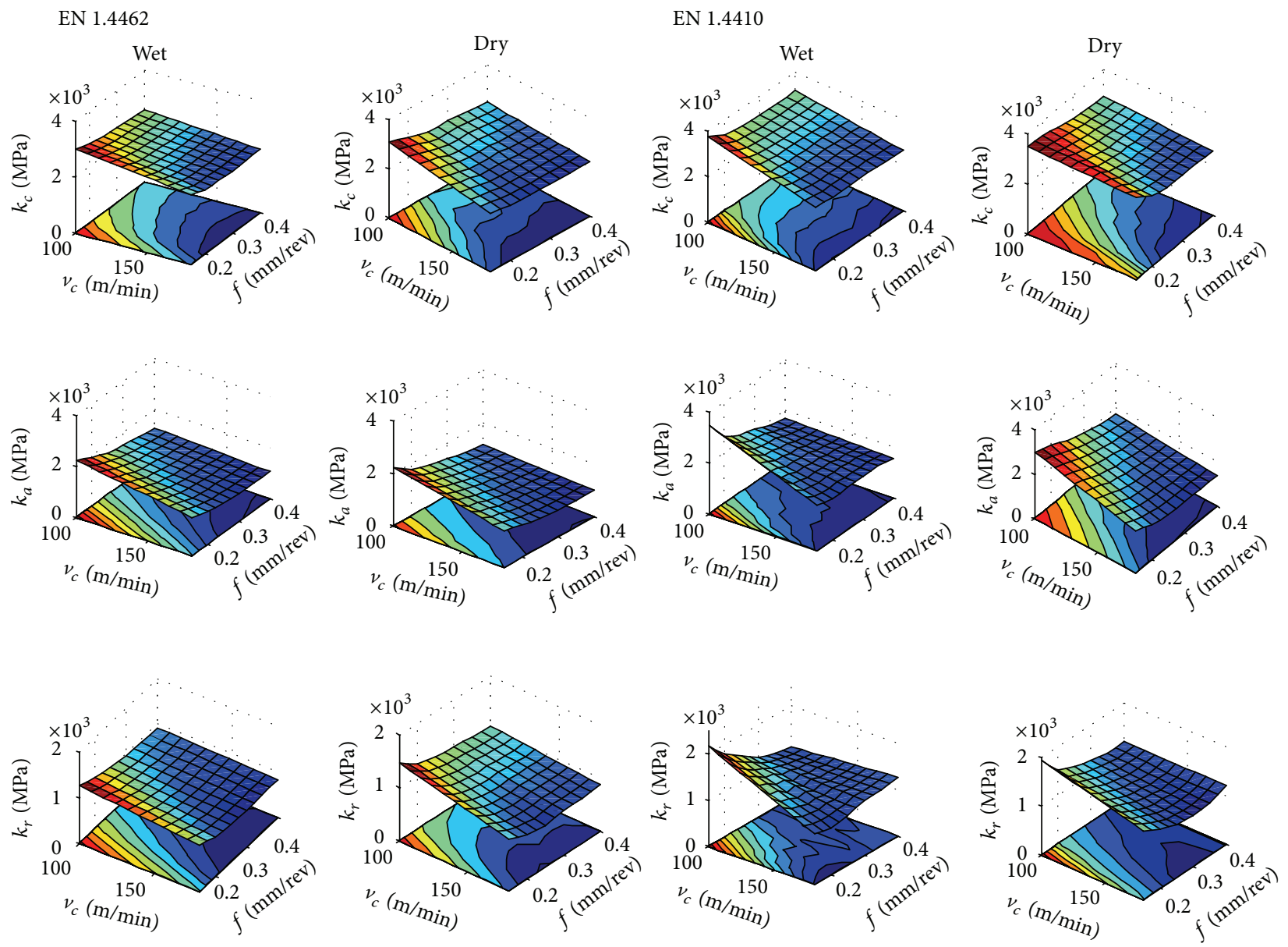

FIGURE 2: Computed specific cutting pressures.

TABLE 4: Analysis of variance for cutting force models.

\begin{tabular}{|c|c|c|c|c|c|c|c|c|}
\hline \multirow{2}{*}{ Proc. cond. } & \multicolumn{4}{|c|}{ EN 1.4462} & \multicolumn{4}{|c|}{ EN 1.4410} \\
\hline & $R^{2}$ & $R_{\text {adj. }}^{2}$ & $F$-value & $P$ value & $R^{2}$ & $R_{\text {adj. }}^{2}$ & $F$-value & $P$ value \\
\hline Dry & 0.99 & 0.99 & 8430 & $7.8 E-16$ & 0.99 & 0.99 & 5310 & $6.25 E-15$ \\
\hline Wet & 0.99 & 0.98 & 4010 & $2.2 E-14$ & 0.99 & 0.99 & 7900 & $1.05 E-15$ \\
\hline Dry & 0.96 & 0.95 & 1660 & $1.2 E-12$ & 0.84 & 0.80 & 350 & $1.24 E-09$ \\
\hline Wet & 0.94 & 0.92 & 1130 & $6.6 E-12$ & 0.95 & 0.93 & 949 & $1.43 E-11$ \\
\hline Dry & 0.97 & 0.96 & 1720 & $9.9 E-13$ & 0.73 & 0.67 & 159 & $4.14 E-08$ \\
\hline Wet & 0.96 & 0.95 & 1060 & $8.8 E-12$ & 0.88 & 0.85 & 457 & $3.76 E-10$ \\
\hline Dry & 0.98 & 0.98 & 3870 & $2.6 E-14$ & 0.96 & 0.95 & 1120 & $6.73 E-12$ \\
\hline Wet & 0.98 & 0.97 & 2250 & $3 E-13$ & 0.98 & 0.97 & 2850 & $1.02 E-13$ \\
\hline
\end{tabular}

separately. It should be noted that the average $k_{1.1}$ at wet cutting is generally seen $5 \%$ lower than $k_{1.1}$ at dry cutting and $k_{1.1}$ of turning EN 1.4410 is generally $25.281 \%$ higher than $k_{1.1}$ of turning EN 1.4462. These results clearly indicate the impact of process conditions and workpiece materials on the amount of energy required to cut $1 \mathrm{~mm}^{2}$ chip cross-sections at $100 \mathrm{~m} / \mathrm{min}$.

4.2. Specific Effective Cutting Power $\left(P_{s}\right)$. It has been suggested that more than $90 \%$ of environmental impact from machine tools is due to electrical energy consumption [11]. Therefore, minimizing this consumption is supposed to significantly improve the sustainability performance of manufacturing systems. To achieve this, the estimation of the energy consumed in machining operation should be accomplished through calculation of the specific effective cutting power (see (7)), which can be defined as the amount of the machine-tool energy required to remove a certain volume of the material. Beside the consumed cutting energy in chip formation, it is comprised of the energy consumed by varieties of machinetool functions such as workpiece handling and movement, cutting fluid system, chip removal, and tool changing. 

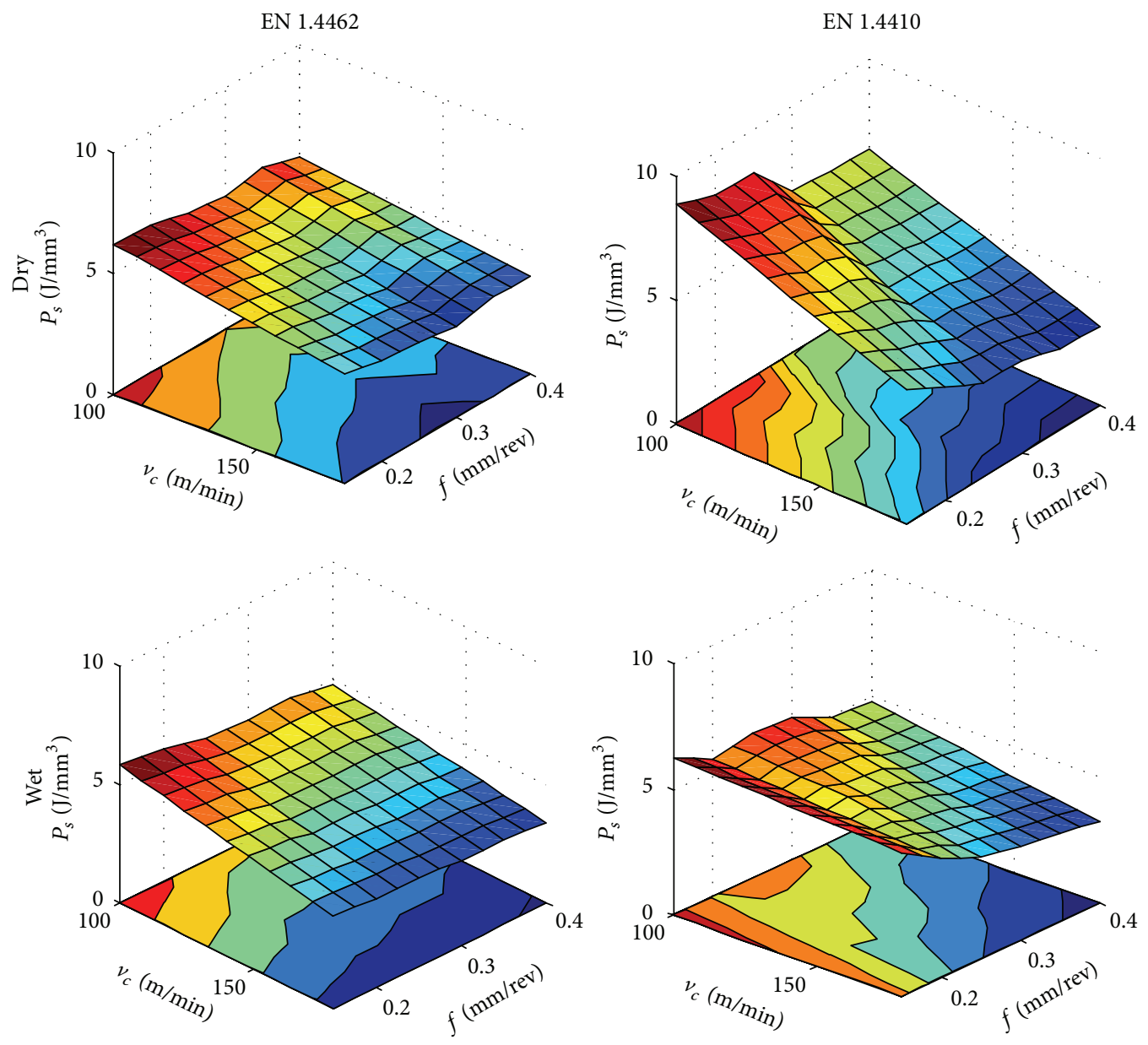

FIgURE 3: Specific effective cutting power.

The specific effective cutting power is supposed to depend on the machinability of the work material, which takes into account the material properties, process conditions, and cutting conditions. The influences of cutting parameters $v_{c}$ and $f$ and process conditions on the specific effective cutting power are shown in Figure 3, from which, the following observations can be made.

(1) Specific effective cutting power is inversely proportional to the cutting speed and feed rate.

(2) Compared to the dry cutting, the wet cutting of EN 1.4462 and EN 1.4410 has shown lower values of $P_{s}$ by $10.82 \%$ and $18.81 \%$, respectively. This is mainly attributed to the lower cutting forces in wet cutting. Therefore, the advantage of employing wet cutting when machining DSSs overtakes its disadvantage of being more energy consumable due to the operation of the coolant pump.

(3) Average $P_{s}$ when machining EN 1.4410 is $12.3 \%$ higher than the average $P_{s}$ when machining EN 1.4462. This result is expected as the latter has inferior mechanical properties and higher percentage of chip breaking constituents such as sulfur and phosphorus (see Table 1).
(4) The effect of the process parameters on the $P_{s}$ results can be modelled using the nonlinear model:

$$
P_{s}=C_{1}\left(\frac{v_{c}}{100}\right)^{C_{2}}(f)^{\left(1-C_{3}\right)},
$$

where $C_{1-3}$ are the model coefficients. The values of model coefficients and the check of adequacy of the models for each turning case are shown in Table 5. It can be seen from this table that the $R^{2}$ values are high and close to 1 , which are usually desirable. The large model $F$-values and small mode $P$ values imply that the models are significant. Therefore, results from the statistical analyses indicate that the developed mathematical models can be successfully applied for predicting the $P_{s}$.

(5) The mean specific cutting pressure can be estimated by the equation:

$$
E_{c}=\frac{k_{c}+k_{a}+k_{r}}{1000} \text { in }\left(\mathrm{J} / \mathrm{mm}^{3}\right)
$$

when cutting EN 1.4462 and EN 1.4410 were found to be $79.7 \%$ and $60.72 \%$ higher than corresponding $P_{s}$ values (see Figure 4). 

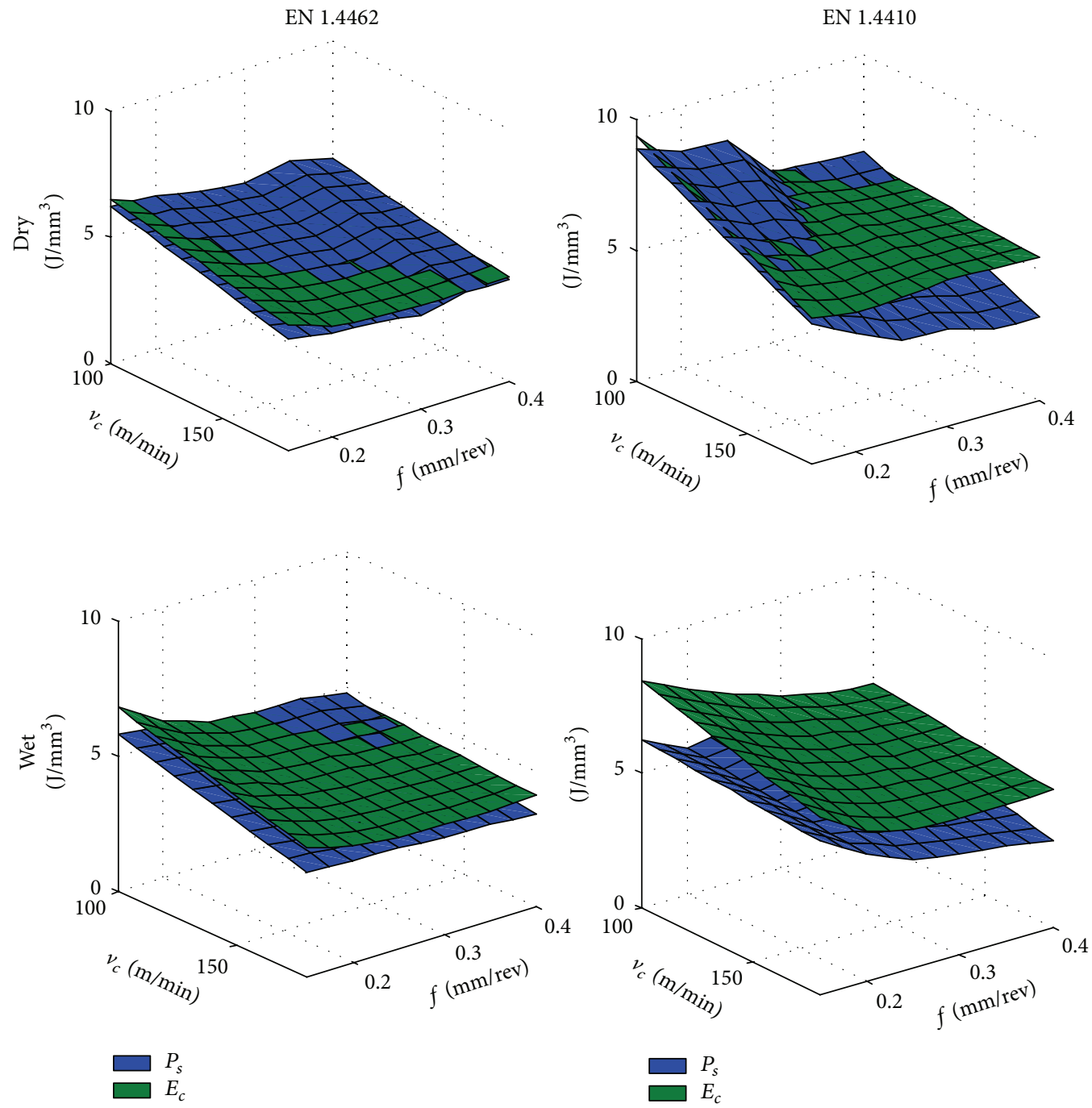

Figure 4: Comparison between $P_{s}$ and $E_{c}$.

(6) The comparison between the effective cutting power $\left(P_{\text {eff. }}\right)$ and the overall consumed cutting power $\left(P_{c}\right)$ (see Figure 5) calculated by (11) has revealed that the average $P_{\text {eff. }}$ is $8.965 \%$ and $33.3195 \%$ higher than average $P_{c}$ for cutting both EN 1.4462 and EN 1.4410, respectively. Results have also showed that the average $P_{c}$ in wet cutting EN 1.4462 and EN 1.4410 were $2.9931 \%$ and $8.27 \%$ lower than the corresponding dry cutting:

$$
P_{c}=\left(\frac{v_{c}}{60}\right)\left(F_{c}+\frac{f}{\pi D} F_{a}\right) \text { in }\left(\mathrm{J} / \mathrm{mm}^{3}\right) .
$$

4.3. The Width of Maximum Flank Wear $\left(V B_{\max }\right)$. The impacts of cutting parameters $v_{c}$ and $f$ and process conditions on the $V B_{\max }$ are shown in Figure 6 and the summary of the findings is presented below.

(1) Based on the observations of tool wear behavior with respect to time during dry machining of DSSs, EN 1.4410 is considered more difficult-to-machine than
TABLE 5: $P_{s}$ model coefficients and check of the models adequacy.

\begin{tabular}{lcccc}
\hline \multirow{2}{*}{ Coeff. } & \multicolumn{2}{c}{ EN 1.4462 } & \multicolumn{2}{c}{ EN 1.4410 } \\
& Dry & Wet & Dry & Wet \\
\hline$C_{1}$ & 4.859 & 4.217 & 4.183 & 3.329 \\
$C_{2}$ & -0.595 & -0.631 & -1.055 & -0.445 \\
$C_{3}$ & 1.128 & 1.163 & 1.421 & 1.360 \\
\hline \multicolumn{5}{c}{ Check of models adequacy } \\
$R^{2}$ & 0.972 & 0.989 & 0.973 \\
$R_{\text {adj. }}^{2}$ & 0.966 & 0.987 & 0.968 & 0.874 \\
$F$-value & $3.35 E+03$ & $7.70 E+03$ & $1.06 E+03$ & $6.29 E+04$ \\
$P$ value & $4.99 E-14$ & $1.17 E-15$ & $8.58 E-12$ & $9.05 E-11$ \\
\hline
\end{tabular}

EN 1.4462. For instance, machining EN 1.4410 at cutting speed value of $180 \mathrm{~m} / \mathrm{min}$ and feed rate value of $0.35 \mathrm{~mm} / \mathrm{rev}$ has resulted in significantly higher wear rate and thus shorter tool life, higher cutting temperature, higher cutting forces, and higher energy consumption than machining EN 1.4462 (see Figure 7). 

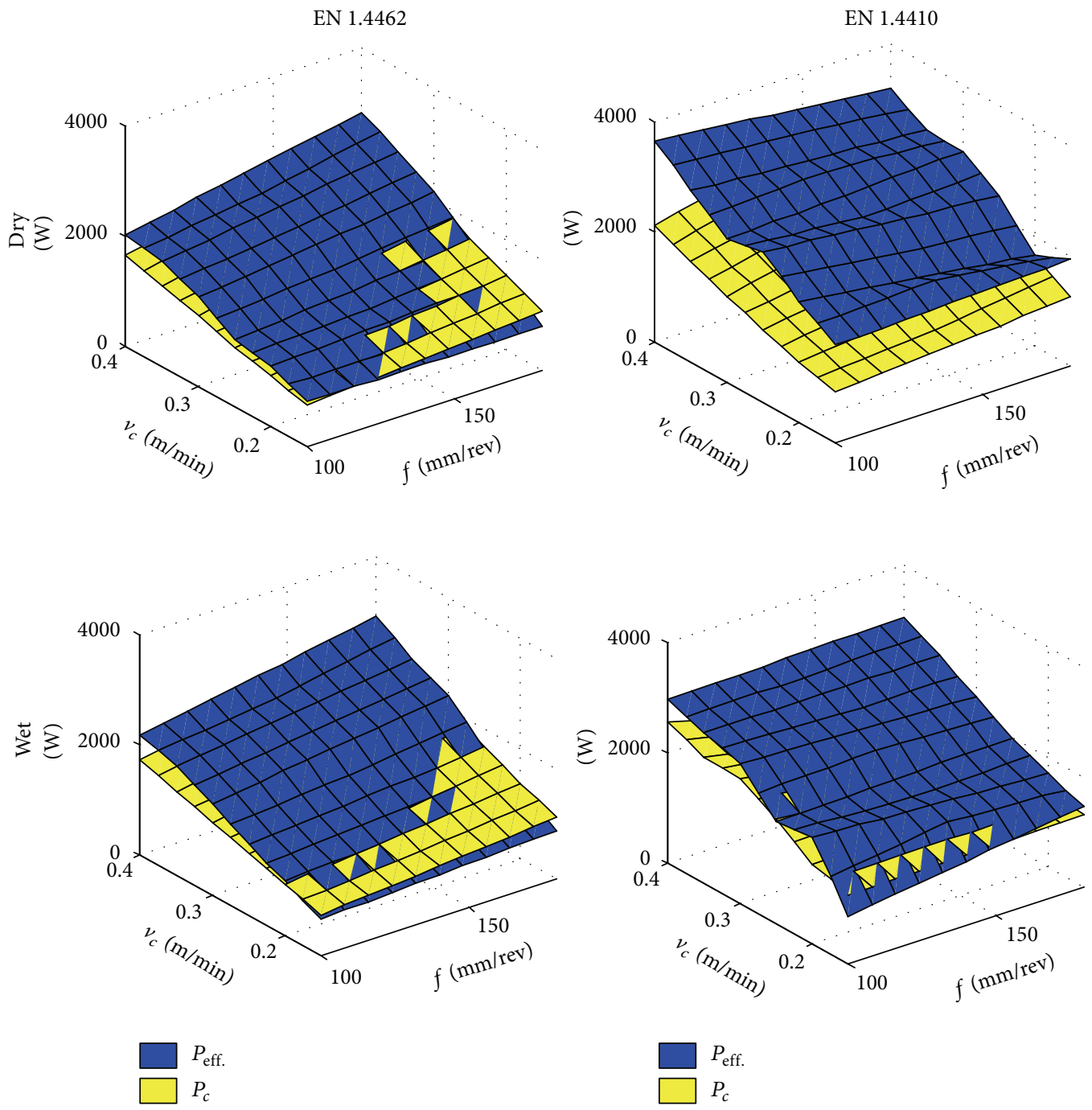

Figure 5: Comparison between $P_{c}$ and $P_{\text {eff. }}$.

Figure 8 shows the average value of recorded cutting forces in dry conditions over $60 \mathrm{sec}$ and $320 \mathrm{sec}$ of machining EN 1.4462 and $20 \mathrm{sec}$ and $40 \mathrm{sec}$ of machining EN 1.4410.

An increasing trend in all cutting forces (main, feed, and radial) over time was observed. However, the largest percentage of cutting force increase was recorded in radial cutting force with $32.933 \%$ and 164.34\% for machining EN 1.4462 and EN 1.4410, respectively. From this perspective, the most suitable parameter to monitor and correlate with progressive tool wear during machining is the radial cutting force component.

(2) The illustration of typical wear forms when machining DSSs are shown in Figure 9. The following can be seen.

(a) Severe adhesion between the chip and the rake face of the tool (BUE) was visible throughout the worn crater area. This is believed to be attributed to the high pressure and temperature encountered in machining ductile materials such as DSSs.

(b) Regardless of the adopted process conditions, chipping of the cutting edge at high feed rate was often observed, which has significantly contributed to acceleration of tool failure. Heavy load and impact when the tool entered and/or extracted the workpiece are considered to be the main reasons behind this phenomenon.

(c) The most dominant tool wear mode under low cutting speed conditions was the notch wear which was typically located near the depth of cut line. These notches act as stress and temperature raisers of the already high mechanical strength, strain hardening rate, fracture toughness, and low conductivity DSSs chips. Flaking occurrence because of the concentrated thermal load 

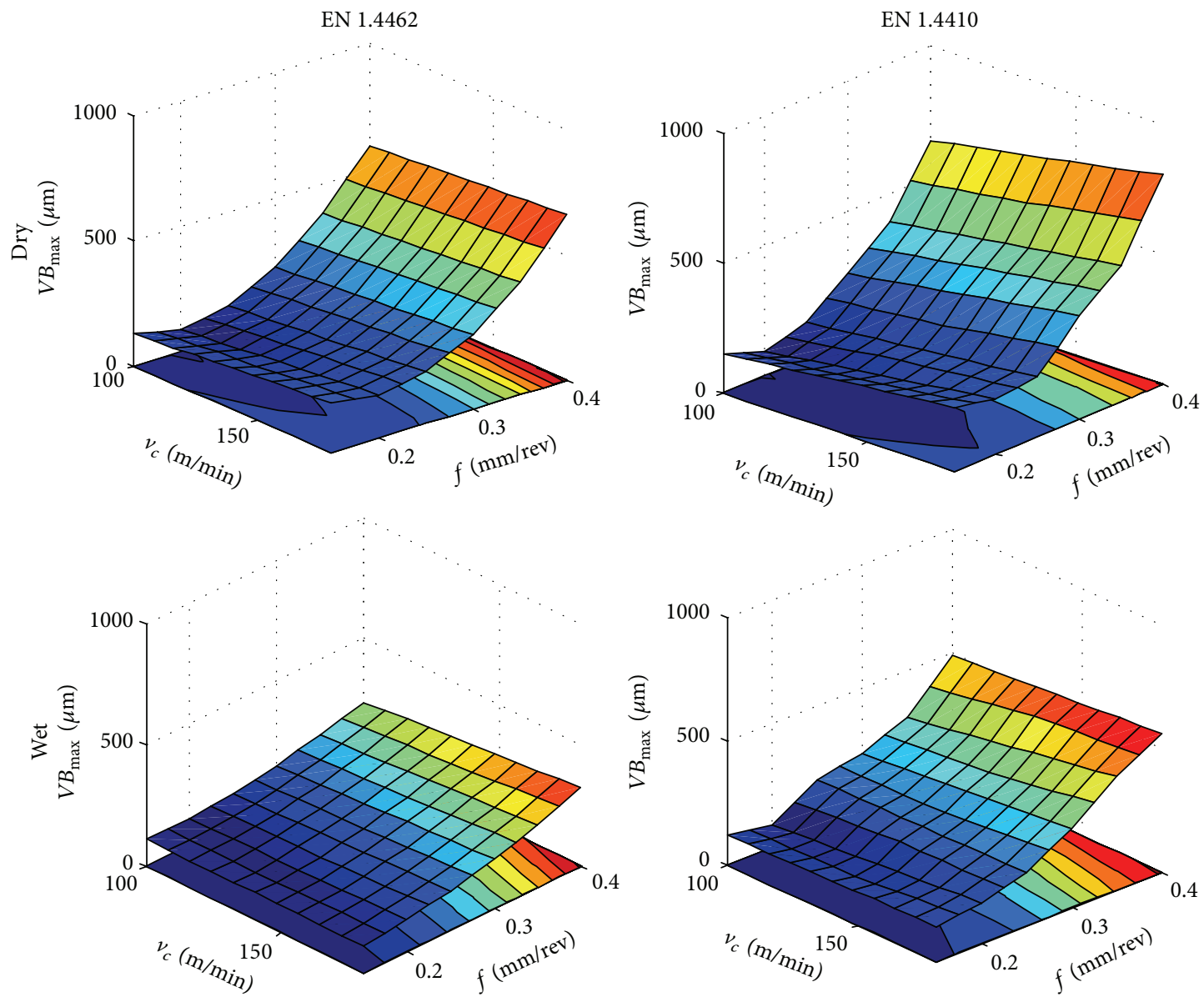

FIgURE 6: The width of maximum flank wear $\left(V B_{\max }\right)$.

is more possible there. Ultimately, the combination of notch wear and flaking caused the cutting edge to fail abruptly.

(d) Another form of the main cutting edge damage is caused by the unfavorable chip morphology and chip flow (see Figure 10). Cutting DSSs at low cutting speed and feed rate has contributed to the formation of strong ribbon and snarled chips with dominant side-curl flow. The chips were entangled around the cutting tool, tool post, and workpiece and damaged to the cutting edge and the workpiece surface. The damage is often propagated along the main cutting edge of the tool with cutting time and had exceeded $5 \mathrm{~mm}$ length of damage in feed rate ranges of $0.15-0.20 \mathrm{~mm} / \mathrm{rev}$.

(e) In addition to the combined notching and flaking effects, nearly equal proportions of soft ferrite and hard austenite grains in the DSS structure make the cutting tool alternate cutting between soft and hard grains; this leads to an automatic tendency to initiate chatter in the cutting system and promote the catastrophic failure of the cutting tools.
(3) To model $V B_{\max }$, an empirical formula described by (8) is applied as follows:

$$
V B_{\max }=\lambda_{1}\left(\frac{v_{c}}{100}\right)^{\lambda_{2}}(f)^{\left(1-\lambda_{3}\right)}
$$

where $\lambda_{1-3}$ are model constants. To check the adequacy of derived models, ANOVA for $95 \%$ confidence interval has been applied. Table 6 summarizes the values of coefficients and adequacy criterion. It can be seen that high correlation coefficients are existing between the experimental and predicted $V B_{\max }$ values and high model $F$-values, and low model $P$ values $(\ll 0.05)$ confirm the significance of the models.

\section{Multiobjective Optimization of Turning DSSs}

The objective of the present study is to simultaneously minimize the resultant cutting force, the specific effective cutting power, and the width of maximum flank wear. The mathematical formulation of the current optimization problem can be stated as follows:

$$
\operatorname{Min}: R\left(v_{c}, f\right) \text {, }
$$


EN 1.4462

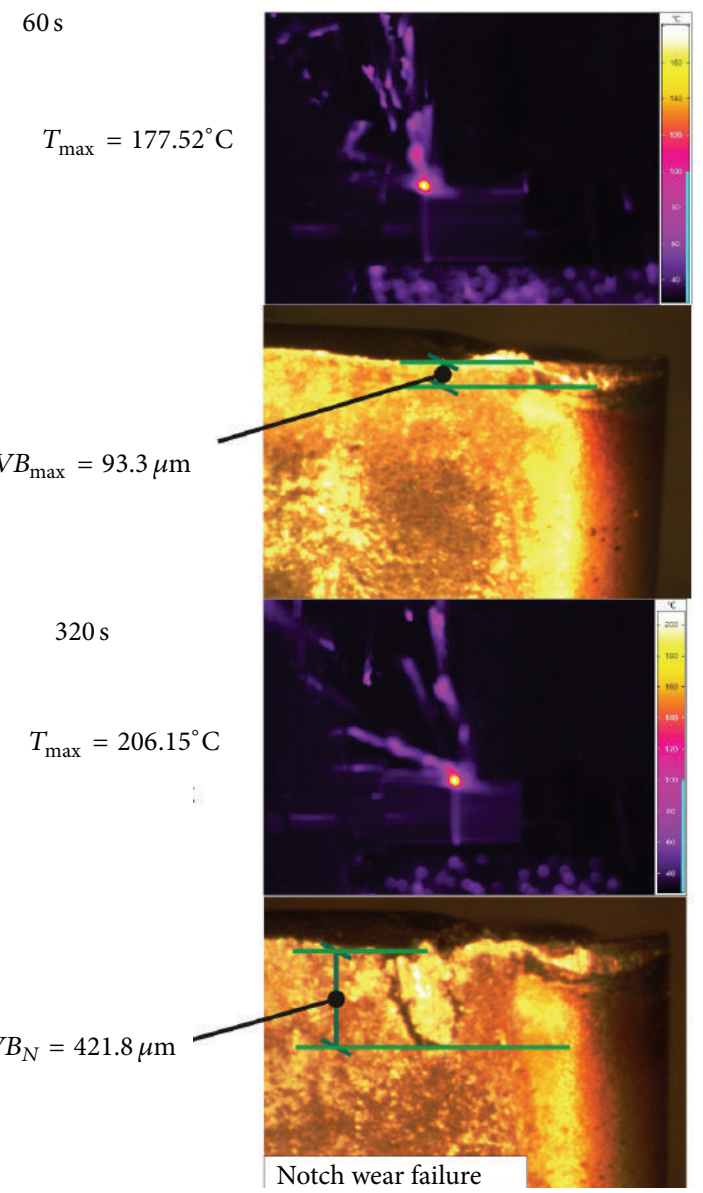

EN 1.4410

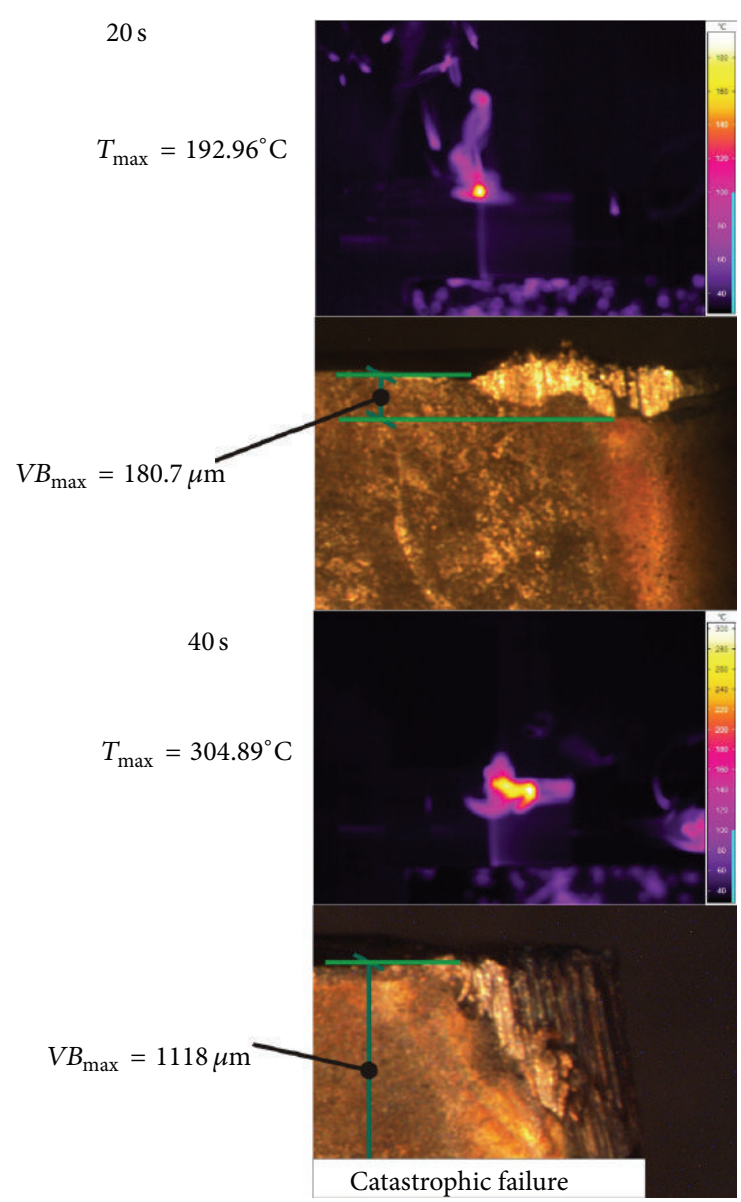

FIGURE 7: Progression of the maximum chip temperature and tool wear pattern with cutting time in dry cutting of DSSs.

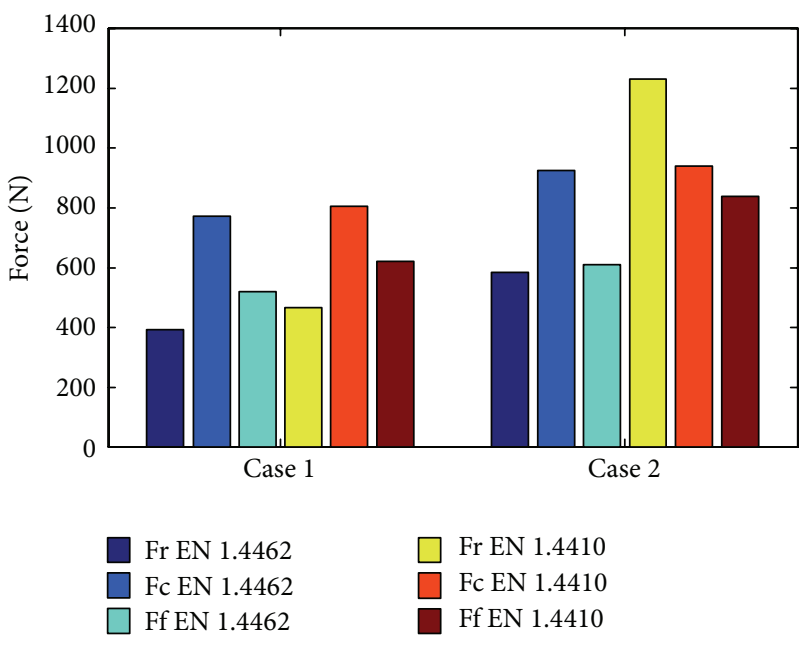

FIGURE 8: Variation of cutting forces with respect to the cutting time.

$$
\begin{aligned}
& \text { Min : } P_{s}\left(v_{c}, f\right), \\
& \text { Min : } V B_{\max }\left(v_{c}, f\right),
\end{aligned}
$$

TABLE 6: $V B_{\max }$ models coefficients and check of their adequacies.

\begin{tabular}{lcccc}
\hline \multirow{2}{*}{ Coeff. } & \multicolumn{2}{c}{ EN 1.4462 } & \multicolumn{2}{c}{ EN 1.4410 } \\
& Dry & Wet & Dry & Wet \\
\hline$\lambda_{1}$ & 4618.4 & 654.091 & 4473.3 & 2369.6 \\
$\lambda_{2}$ & 0.29156 & 0.49853 & 0.50425 & 0.40716 \\
$\lambda_{3}$ & -1.335 & -0.15483 & -1.236 & -0.8276 \\
\hline \multicolumn{5}{c}{ Check of models adequacy } \\
$R^{2}$ & 0.908 & 0.947 & 0.904 \\
$R_{\text {adj. }}^{2}$ & 0.888 & 0.936 & 0.882 & 0.957 \\
$F$-value & $1.17 E+02$ & $4.55 E+02$ & $1.10 E+02$ & $3.15 E+02$ \\
$P$ value & $1.56 E-07$ & $3.84 E-10$ & $2.04 E-07$ & $1.98 E-09$ \\
\hline
\end{tabular}

subjected to the following constraints:

(1) arithmetic average roughness $\left(R_{a}\right)$

$$
R_{a}=\frac{0.032 f^{2}}{r_{\varepsilon}} \leq 2 \mu \mathrm{m},
$$




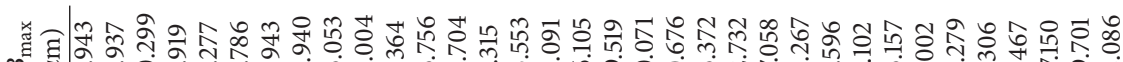

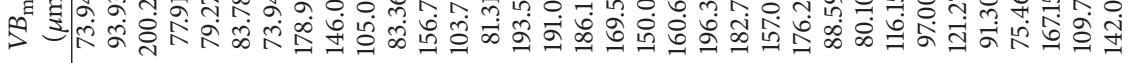

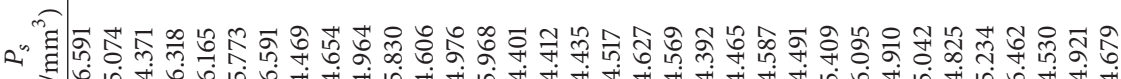

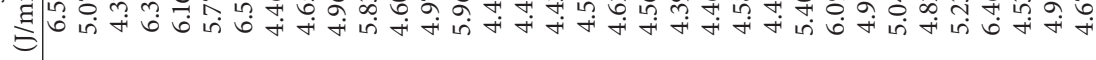

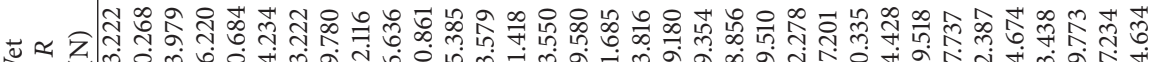

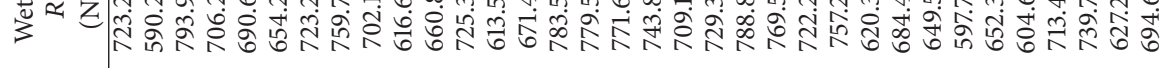

齐

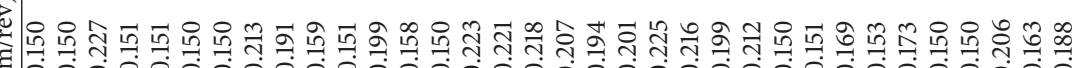
|l 0000000000000000000000000000000

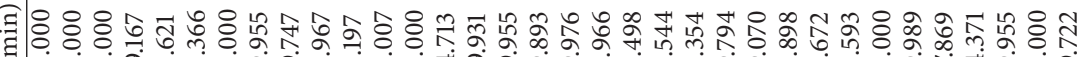

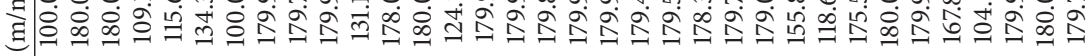

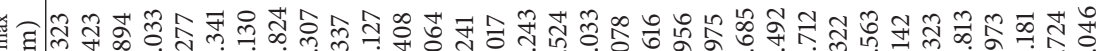

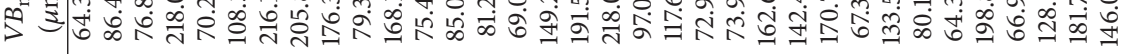

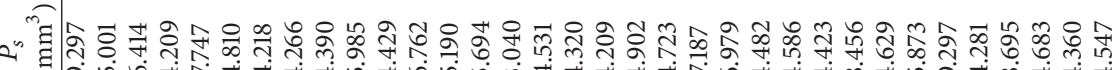

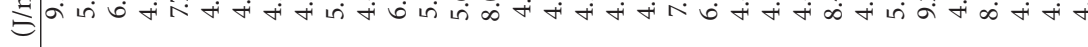

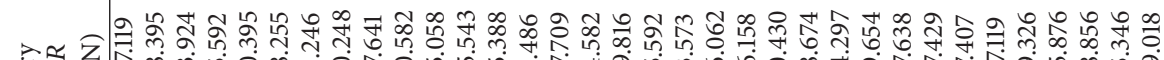

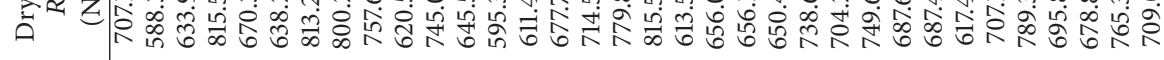

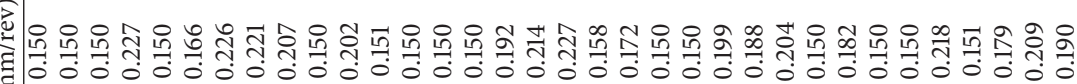

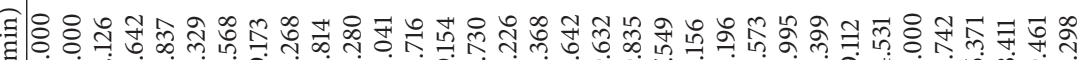

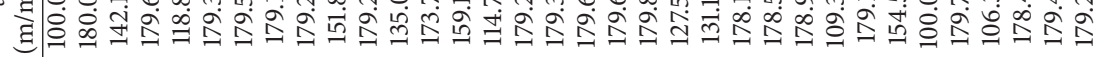

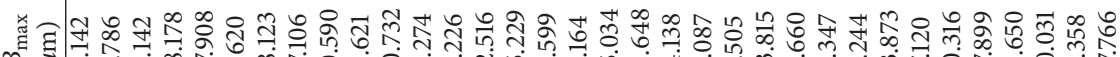

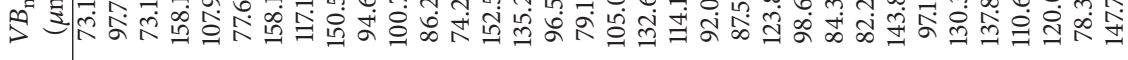

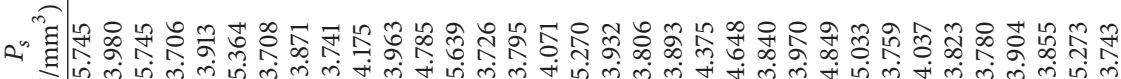

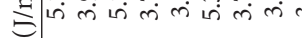

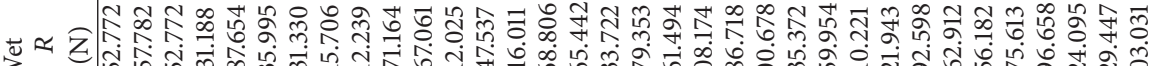

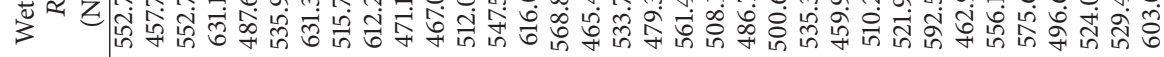

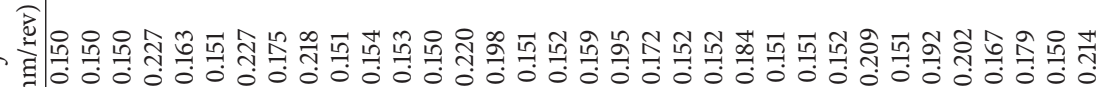
实

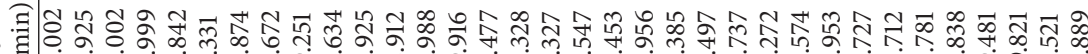

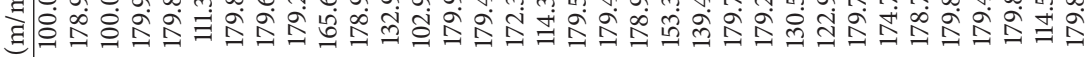

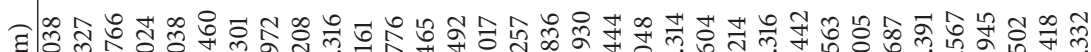

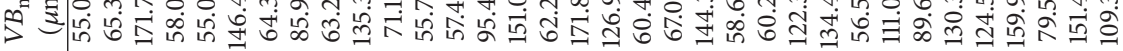

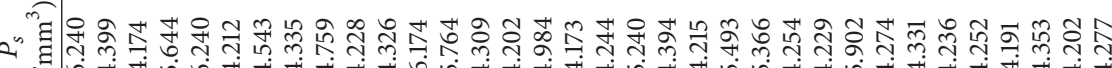

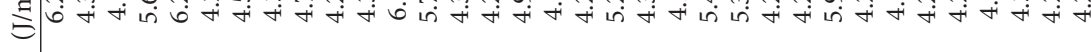

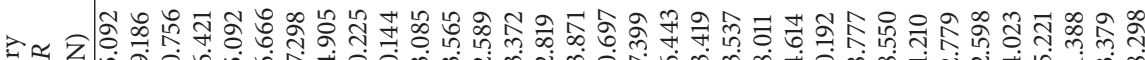

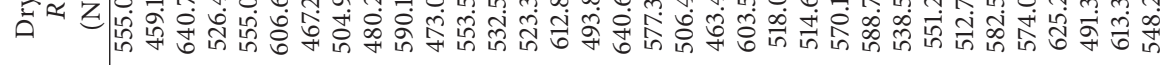
窇

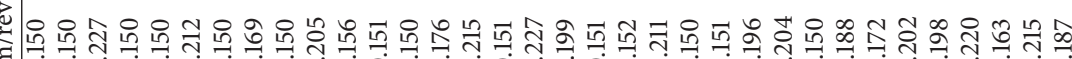
気

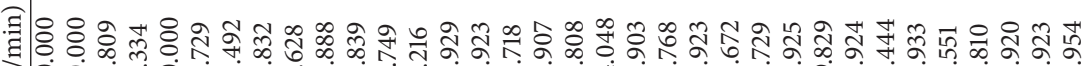

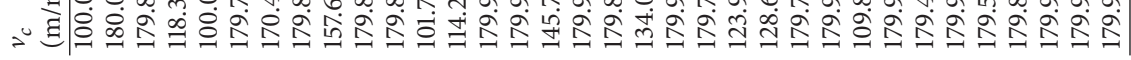




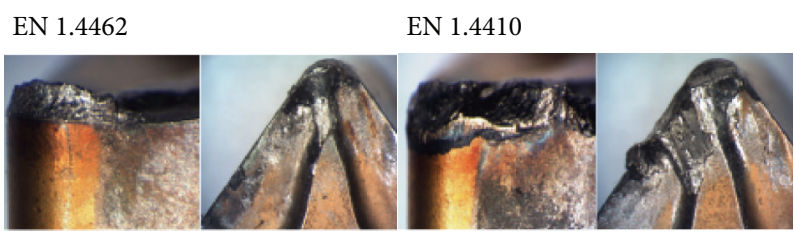

(a)

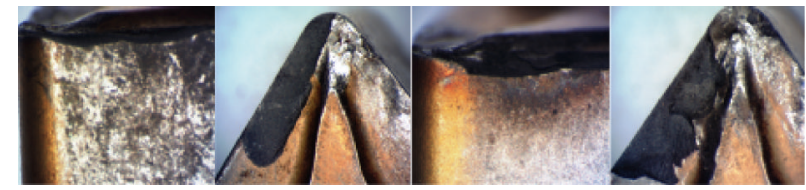

(b)

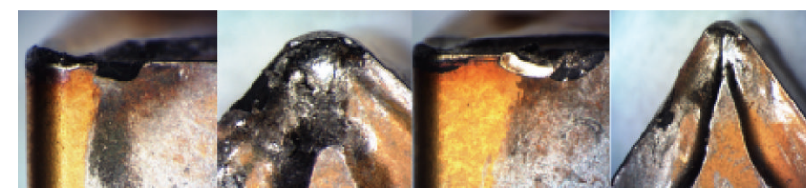

(c)

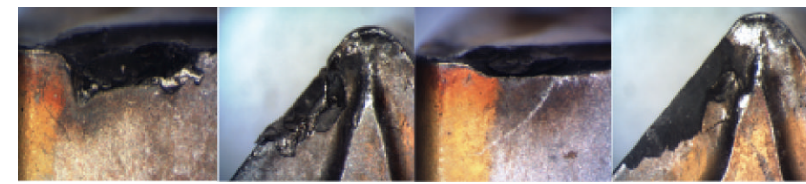

(d)

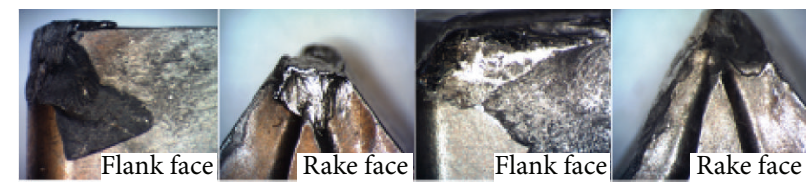

(e)

FIGURE 9: Wear patterns observed on the flank and rake face of cutting tools under dry and wet machining of DSSs.

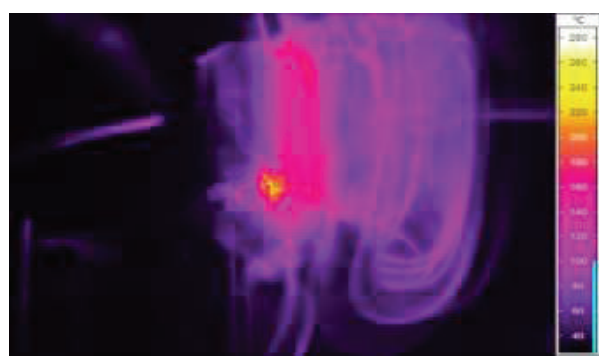

(a)

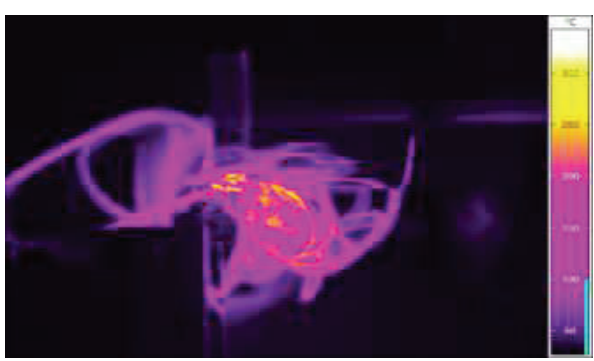

(b)

FIGURE 10: Entanglement of chips around the cutting tool and workpiece at $v_{c}=100 \mathrm{~m} / \mathrm{min}$ and $f=0.15 \mathrm{~mm} / \mathrm{rev}$ : (a) EN 1.4462 , (b) EN 1.4410 .

(2) cutting parameters lower and upper bounds:

$$
\begin{aligned}
& 100 \leq v_{c} \leq 180 \mathrm{~m} / \mathrm{min}, \\
& 0.15 \leq f \leq 0.4 \mathrm{~mm} / \mathrm{rev} .
\end{aligned}
$$

The proposed MOBA is implemented in Matlab. The computing time was less than a minute, depending on the iteration number and population size. It was found that the best population size $(n)$, loudness reduction $(\alpha)$, and pulse reduction rate $(\gamma)$ were $40,0.8$, and 0.8 , respectively. Optimization results have shown that MOBA is very efficient and consistently converges to the sets of optimal solutions. Figure 11 shows the Pareto optimal frontier points for different process conditions, at which the designers can determine the final solutions depending on their preferences. The final optimum $v_{c}$ and $f$ and their corresponding $R, P_{s}$, and $V B_{\max }$ are shown in Table 7. These process parameters are the Pareto optimal process parameters that should be shown to the decision 


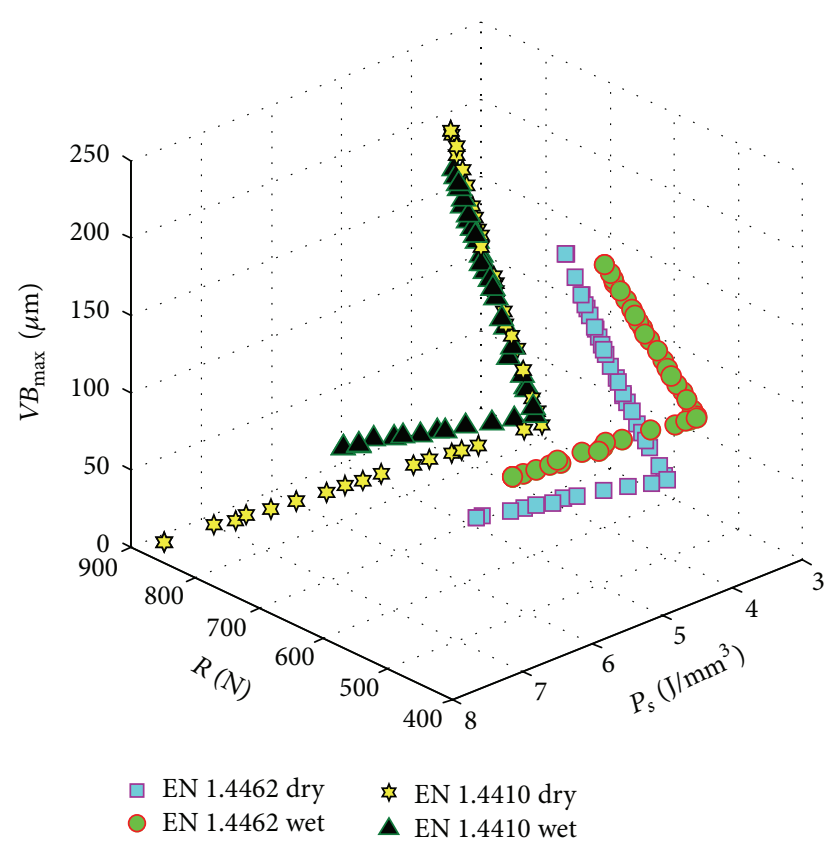

FIGURE 11: Pareto front points.

maker to simultaneously achieve the desired objectives in turning of the DSSs.

\section{Conclusions}

An experimental investigation on cutting of EN 1.4462 and EN 1.4410 duplex stainless steels was presented. A modelling technique based on the modified Kienzle's equation was adopted to model the performances and ANOVA tests were performed to check the models adequacies. With the aid of three-dimensional surface plots, the effects of workpiece materials, process, and cutting conditions on the different cutting performances have been analysed and proper conclusion points have been drawn. Results of the early stages of this study have shown that the values of no-beneficial performances when cutting EN 1.4410 were generally higher than those of cutting EN 1.4462, and in comparison to the dry cutting, wet cutting has shown a general improvement in the machining performance.

This paper also presented multiobjective optimization of machining duplex stainless steels based on the natureinspired metaheuristic bat algorithm (MOBA). Three objectives are minimized simultaneously: resultant cutting force, specific effective cutting power, and maximum flank wear. Arithmetic average roughness has been included in the formulation of the optimization problem as a constraint. Results of optimization have shown that MOBA is very efficient and consistently converges to the sets of optimal solutions. It has provided Pareto frontiers of nondominated solution sets for optimum cutting conditions, providing decision makers with a resourceful and efficient means of achieving it. In addition to Pareto's front graph, the paper is complemented with numerical outcomes.

\section{Conflict of Interests}

The authors declare that there is no conflict of interests regarding the publication of this paper.

\section{References}

[1] I. A. Armas and S. M. Degalaix, Duplex Stainless Steels, ISTE Ltd, London, UK, 2009.

[2] E. C. Bordinassi, G. F. Batalha, S. Delijaicov, N. B. de Lima, and S. Paulo, "Superficial integrity analysis in a super duplex stainless steel after turning," Journal of Achievements in Materials and Manufacturing Engineering, vol. 18, pp. 335-338, 2006.

[3] G. Królczyk, S. Legutko, and M. Gajek, "Predicting the surface roughness in the dry machining of duplex stainless steel (DSS)," Metalurgija, vol. 52, no. 2, pp. 259-262, 2013.

[4] G. Królczyk, M. Gajek, and S. Legutko, "Effect of the cutting parameters impact on tool life in duplex stainless steel turning process," Tehnicki Vjesnik, vol. 20, no. 4, pp. 587-592, 2013.

[5] J. Nomani, A. Pramanik, T. Hilditch, and G. Littlefair, "Machinability study of first generation duplex (2205), second generation duplex (2507) and austenite stainless steel during drilling process," Wear, vol. 304, no. 1-2, pp. 20-28, 2013.

[6] C. D. Oliveira Jr., A. Diniz, and R. Bertazzoli, "Correlating tool wear, surface roughness and corrosion resistance in the turning process of super duplex stainless steel," Journal of the Brazilian Society of Mechanical Sciences and Engineering, vol. 36, no. 4, pp. 775-785, 2013.

[7] D. Philip Selvaraj, P. Chandramohan, and M. Mohanraj, "Optimization of surface roughness, cutting force and tool wear of nitrogen alloyed duplex stainless steel in a dry turning process using Taguchi method," Measurement, vol. 49, no. 1, pp. 205-215, 2014.

[8] Coello CAC, "An updated survey of evolutionary multiobjective optimization techniques: state of the art and future trends," in Proceedings of the Congress on Evolutionary Computation (CEC '99), pp. 3-13, Washington, DC, USA, July 1999.

[9] A. Konak, D. W. Coit, and A. E. Smith, "Multi-objective optimization using genetic algorithms: a tutorial," Reliability Engineering and System Safety, vol. 91, no. 9, pp. 992-1007, 2006.

[10] X.-S. Yang, "Multi-objective optimization," in Nature-Inspired Optimization Algorithms, X.-S. Yang, Ed., chapter 14, pp. 197211, Elsevier, Oxford, UK, 2014.

[11] CECIMO, Concept Description for CECIMO's Self -Regulatory Initiative (SRI) for the Sector Specific Implementation of the Directive 2005/32/EC (EuP Directive) Goal of the SRI Scope of the SRI, 2011. 

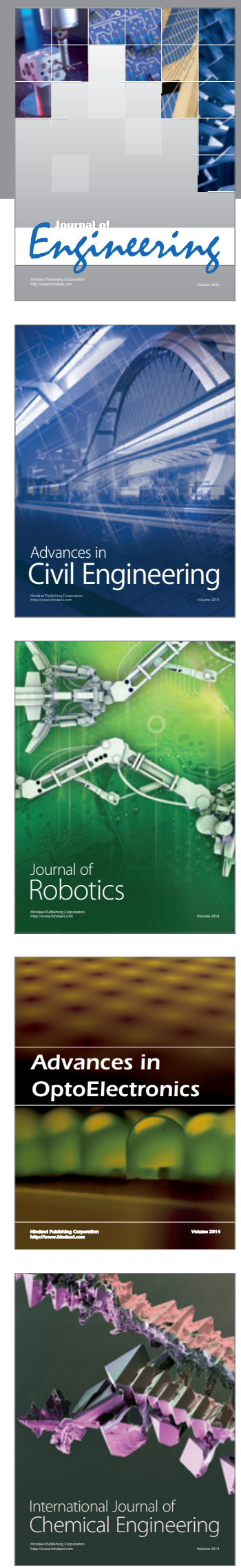

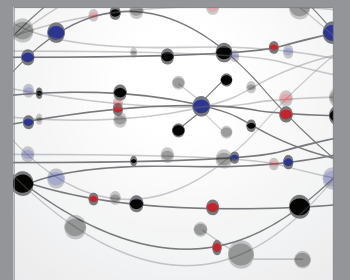

The Scientific World Journal
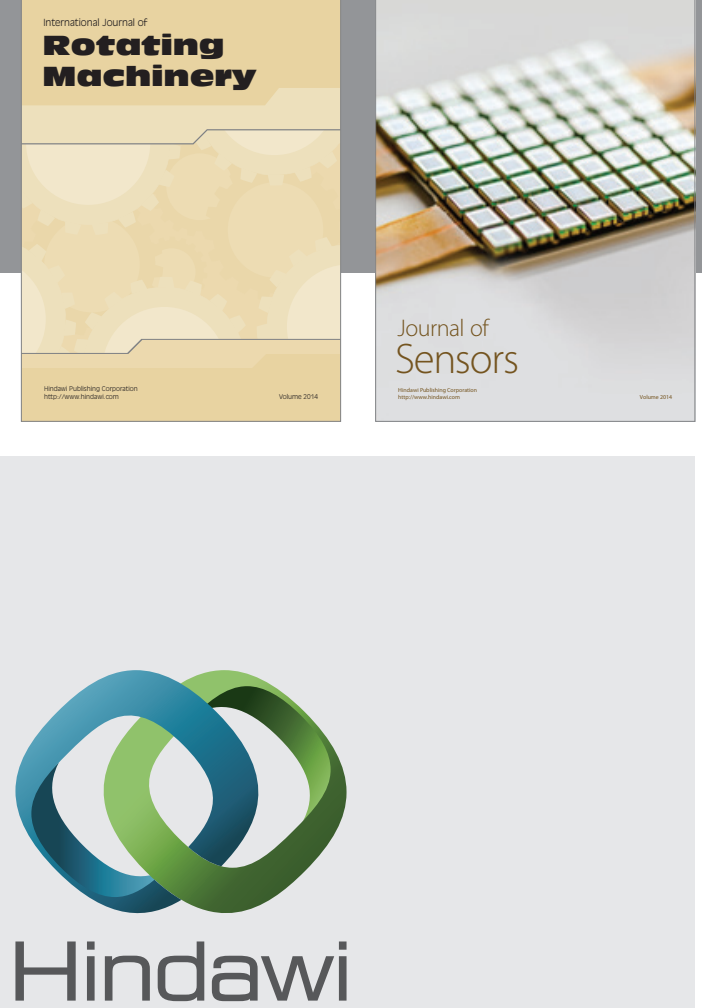

Submit your manuscripts at http://www.hindawi.com
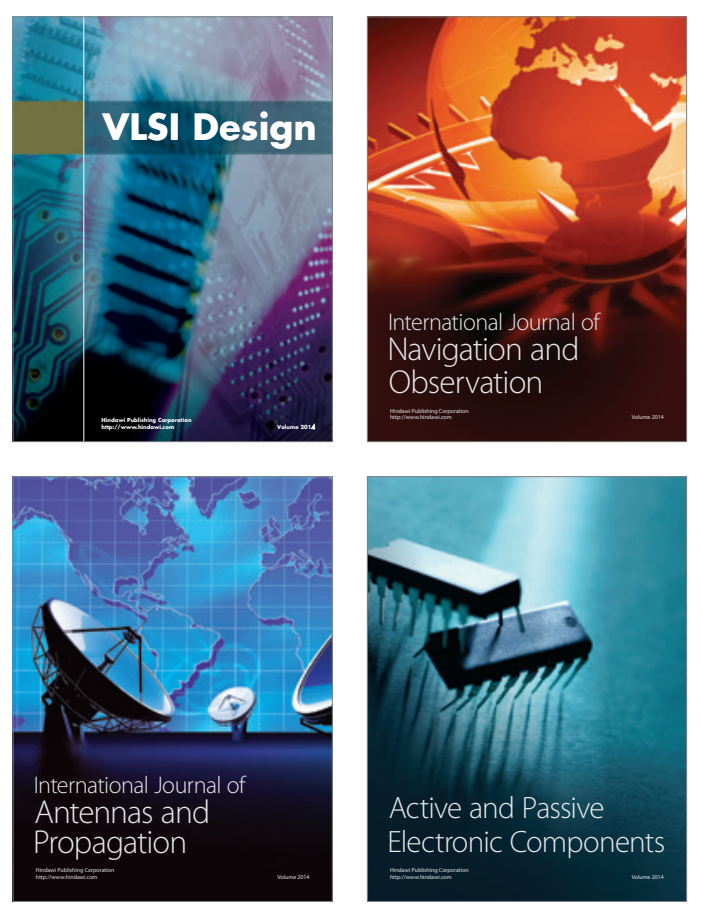
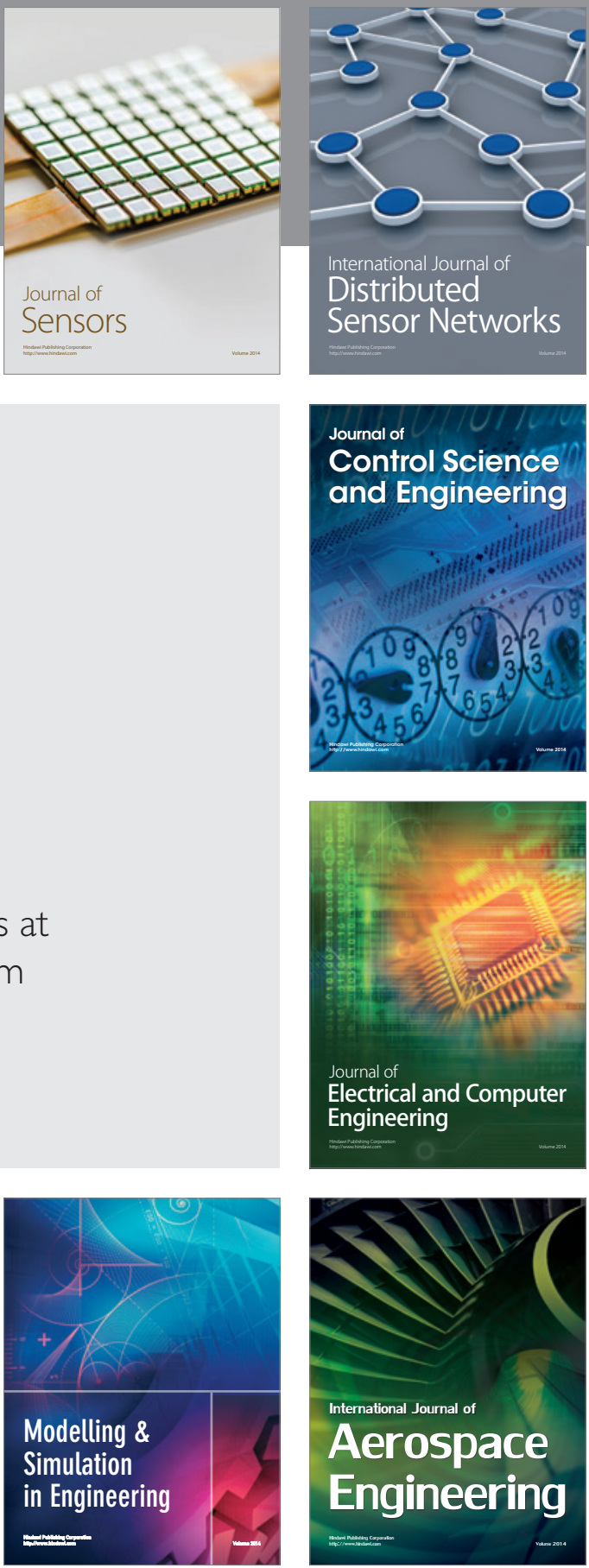

Journal of

Control Science

and Engineering
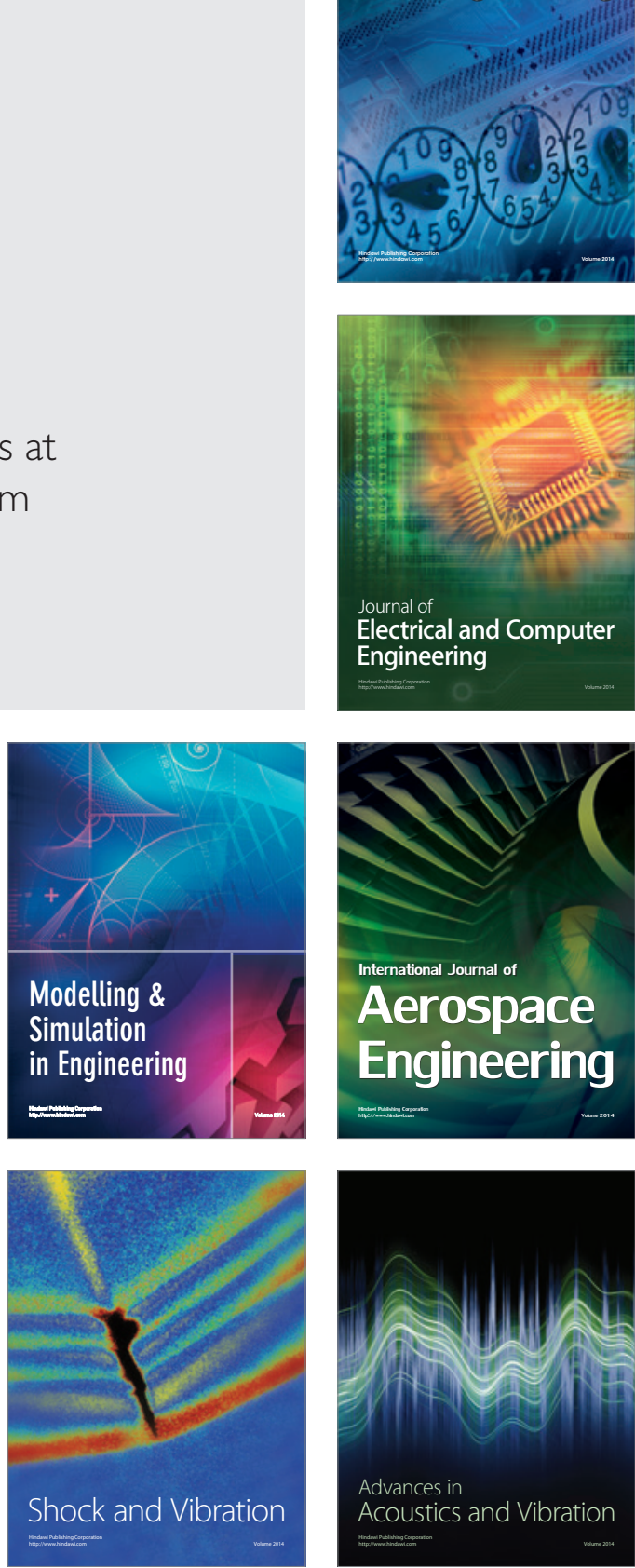